\title{
A FORMAÇÃO DOCENTE E O PROCESSO DE CONSTRUÇÃO DO SER PROFESSOR
}

\author{
TEACHING TRAINING AND THE CONSTRUCTION PROCESS OF BEING A TEACHER \\ FORMACIÓN DOCENTE Y EL PROCESO DE CONSTRUCCIÓN DEL SER PROFESOR
}

\author{
Maria de Lourdes Tavares Magalhães \\ Mestra em educação brasileira. Professora temporária da Universidade Regional do Cariri - URCA. Crato, \\ Ceará, Brasil. \\ Orcid: 0000-0001-5831-1918. \\ E-mail: lourdesmari05@yahoo.com.br.
}

\author{
Bernadete de Souza Porto \\ Doutora em educação brasileira. Professora efetiva da Universidade Federal do Ceará - UFC. Fortaleza, \\ Ceará, Brasil. \\ Orcid: 0000-0003-2286-3811. \\ E-mail: bernadete.porto@gmail.com.
}

\begin{abstract}
RESUMO
O presente estudo discute a formação docente, especificamente a inicial, bem como o processo de construção do entendimento do que é ser professor; isto é, compreender os saberes necessários e intrínsecos à atividade docente. Nesse contexto, entende-se que o conceito de formação está ligado ao significado de ensinar e aprender e, mais ainda, ao papel que este profissional desempenha na sociedade contemporânea. Sinalizamos que o processo de formação docente é historicamente determinado, o que requer a compreensão sistemática acerca da função social da profissão. Para tanto, elegemos os objetivos que nortearão o nosso estudo. Assim, como objetivo geral, estabelecemos: compreender a relação entre a formação inicial e o processo de constituição dos saberes docentes. Como objetivos específicos, definimos: conceituar formação inicial; identificar suas características basilares e analisar as principais tendências formativas presentes na formação inicial de professores. A metodologia adotada é a pesquisa qualitativa, especialmente a bibliográfica. Desse modo, para compreendermos o tema, consultamos obras de autores que tratam do assunto. Na conclusão, apontamos que a formação docente não é restrita à transmissão dos conteúdos curriculares, em uma acepção puramente técnica e instrumental, mas, ao contrário, está ancorada a uma concepção crítica da educação, que concebe o docente como um intelectual críticoreflexivo e consciente da sua função social.
\end{abstract}

Palavras-chave: Professor. Formação. Docente. Saberes. Tendências.

\begin{abstract}
The present study discusses teacher training, precisely the initial one, and the process of building the understanding of what it means to be a teacher; that is, understanding the necessary and intrinsic knowledge of teaching activity. In this context, it is understood that the concept of training is linked to the meaning of teaching and learning and, even more, to the role that this professional plays in contemporary society. We indicate that the process of teacher education is historically determined, which requires a systematic understanding of the social function of the profession. Therefore, we chose the objectives that will guide our study. Thus, as a general objective, we established: to understand the relationship between initial training and the process of constitution of teaching knowledge. As specific objectives, we determined: to conceptualize initial training; identify its basic characteristics and analyze the main training
\end{abstract}


trends present in the initial teacher education. The methodology adopted is qualitative research, especially bibliographic. Hence, to understand the topic, we consulted works of the authors who deal with the subject. In the conclusions, we point out that teacher education is not restricted to the transmission of curricular content, in a purely technical and instrumental sense, but, on the contrary, it is anchored to a critical conception of education, which conceives the teacher as a critical-reflective intellectual and aware of its social function.

Keywords: Professor. Training. Teacher. Knowledge. Tendencies.

\section{RESUMEN}

El presente estudio discute la formación docente, especialmente la inicial, así como el proceso de construir la comprensión de lo que significa ser maestro, es decir, comprender el conocimiento necesario e intrínseco a la actividad docente. En este contexto, se entiende que el concepto de formación está estrechamente relacionado con el significado de enseñanza y aprendizaje y, más aún, sobre el papel que desempeña este profesional en la sociedad contemporánea. Señalamos que el proceso de formación del profesorado está históricamente determinado, lo que requiere una comprensión sistemática de la función social de la profesión. Para ello, elegimos los objetivos que orientarán nuestro estudio. Así, como objetivo general establecemos: comprender la relación entre la formación inicial y el proceso de construcción del conocimiento docente. Como objetivos específicos, definimos: conceptualizar la formación inicial; Identificar sus características básicas y hacer un análisis de las principales tendencias de formación presentes en la formación inicial del profesorado. La metodología adoptada es la investigación cualitativa, especialmente bibliográfica. De esta manera, para comprender el tema consultamos obras de autores que lo discuten. En la conclusión, señalamos que la formación docente no se limita a la transmisión de contenidos curriculares, en un sentido puramente técnico e instrumental, sino que, por el contrario, está anclada en una concepción crítica de la educación, que concibe al profesor como un intelectual críticoreflexivo, consciente de su función social.

Palabras-clave: Profesor. Formación. Docente. Conocimiento. Tendencias.

\section{INTRODUÇÃO}

O presente artigo $^{1}$ sinaliza a importância da formação inicial, no que concerne à aquisição dos saberes necessários à docência e à compreensão dos elementos que compõem o processo de ensino aprendizagem. Por ser a primeira etapa do processo formativo, ela repercute em todas as outras, configurando-se como a base de sustentação para o desenvolvimento do magistério. Assim, embora seja correto admitir que a aquisição desses saberes não tenha início apenas na formação inicial, não podemos deixar de reconhecer que ela é uma área especializada de apropriação sistemática dos instrumentos teóricos e práticos que darão suporte à atividade do ensino. O presente artigo tem como objetivo geral compreender a relação entre a formação inicial e o processo de constituição dos saberes docentes e como objetivos específicos: conceituar

\footnotetext{
${ }^{1}$ O presente artigo é parte integrante da dissertação de mestrado, cujo título é o seguinte: Os Saberes Pedagógicos de Professores do Curso de Pedagogia da Universidade Regional do Cariri/URCA - um estudo sobre a racionalidade pedagógica nas narrativas docentes. De autoria de Maria de Lourdes Tavares Magalhães, orientada pela professora Doutora Bernadete de Souza Porto.
} 
formação inicial; identificar suas características basilares; e realizar uma análise das principais tendências formativas presentes na formação inicial de professores.

Elegemos a metodologia qualitativa como caminho profícuo de estudo, pois ela nos possibilitará o alcance dos objetivos propostos. Utilizaremos, portanto, a pesquisa bibliográfica como principal fonte de referência. Para Severino (2007), a pesquisa bibliográfica é aquela proveniente “[...] de pesquisas anteriores, em documentos impressos, como livros, artigos, teses e etc. Utiliza-se de dados ou de categorias teóricas já trabalhadas por outros pesquisadores e devidamente registrados. " (SEVERINO, 2007, p. 22).

Para tanto, nossa metodologia foi estruturada de acordo com as seguintes etapas: primeira etapa: seleção dos autores e dos documentos disponíveis, ou seja, foram identificados os diversos autores que tratam do assunto em questão, para que logo em seguida, pudéssemos selecionar as obras ou documentos disponíveis. Segunda etapa: leitura e fichamento das obras e documentos disponíveis. Nesse momento procedemos à leitura, fichamento e interpretação do material selecionado na primeira etapa. Terceira etapa: escrita do artigo, nesse contexto, somente nos foi possível escrever o presente artigo tendo como suporte teórico o pensamento dos diversos autores sobre a formação docente. Após serem explanados os objetivos e a metodologia que norteiam esse estudo, passemos então para o próximo subitem.

\section{Formação inicial: espaço privilegiado de constituição dos saberes docentes}

A formação de professores, é uma temática presente desde o início da sua história e ocupa lugar de destaque nas pesquisas que elegem a educação e o ensino como objeto de estudo. Indubitavelmente, não podemos discutir sobre a qualidade da educação do nosso país sem compreender os princípios básicos que regem a formação de professores nas nossas universidades e como os saberes que esses profissionais produzem, no cotidiano da sala de aula, podem ser estudados e problematizados nos processos formativos. No entanto, como podemos conceituar formação docente? Em resposta a essa pergunta, Veiga (2010, p. 16) argumenta que:

O termo "formação" se insere como elemento do desenvolvimento profissional e de crescimento dos docentes em seu trabalho pedagógico e em sua trajetória, 
integrando as dimensões pessoais, profissionais e sociais na constituição de sua identidade como professor autônomo, reflexivo, crítico e solidário.

Compreendemos, ainda, que, a formação está relacionada ao permanente desenvolvimento profissional dos docentes, o que envolve a busca coletiva, isto é, dos professores, instituições de ensino e órgãos públicos responsáveis pelo regimento da educação do país, pelo melhoramento e qualidade desta formação. Em outra fonte, Veiga (2014, p. 330) nos indica o seguinte:

A formação significa a construção de conhecimentos relacionados a diferentes contextos sociais, culturais, educacionais e profissionais. Formar não é algo pronto, que se completa ou finaliza. Formação é um processo permanente. É interdisciplinar, por articular conhecimentos científicos, éticos, pedagógicos, experienciais.

Portanto, a formação inicial é, sem dúvida, um espaço privilegiado de aquisição de conhecimentos, os quais possuem naturezas variadas, como enfatizado nesta citação. Ela é também, um espaço de constituição dos saberes dos professores, pois é nela que formandos deverão se colocar no papel de aprendizes da prática docente, ao mesmo tempo que deverão analisar os saberes do cotidiano dos professores e confrontá-los com os conhecimentos produzidos pelas teorias da educação.

García (1995) discorre, também, sobre o conceito de formação de professores, ao enfatizar a ideia de que a formação é algo sistemático e organizado, e deve, portanto, ser concebida como uma área de conhecimento e investigação. Esta possui, como principal objeto de estudo, os processos mediante os quais os professores aprendem e desenvolvem a sua competência profissional; tal competência pode ser entendida como a capacidade de exercer sua profissão além dos limites da sala de aula, sabendo também exercê-la na elaboração dos projetos educativos e curriculares das instituições de ensino onde trabalham. Segundo o autor em destaque, a formação de professores:

[...] estuda os processos através dos quais os professores - em formação ou em exercício - se implicam individualmente ou em equipe, em experiências de aprendizagem através das quais adquirem ou melhoram os seus conhecimentos, competências e disposições, e que lhes permite intervir profissionalmente no desenvolvimento do seu ensino, do currículo e da escola, com o objetivo de melhorar a qualidade da educação que os alunos recebem (GARCíA, 1995, p. 26).

Almeida (2012, p. 81), acrescenta o fato de ser na formação inicial que o professor compreende a intrínseca relação entre teoria e prática, adquire a capacidade de olhar para si, compreende o ensino e a aprendizagem como aspectos inter-relacionados e, 
finalmente, que ele concebe a ação docente como uma prática social viva, contextualizada e transformadora. Neste sentido, a formação inicial tem grande importância, pois, como dizem Mendes Sobrinho e Carvalho, (2006, p. 48), ela

[...] constitui momento singular de contatos e interações com os saberes iniciais da profissão, postulados na perspectiva de oportunizar aos futuros professores as habilidades e os saberes necessários para vivenciar a prática educativa.

Compreende-se, portanto, que a formação inicial instrumentaliza o professor com as ferramentas conceituais e práticas para que este possa exercer a docência com qualidade. Neste sentido, a formação efetiva-se a partir "[...] da análise sistemática das práticas à luz das teorias existentes, da construção de novas teorias". (PIMENTA, 2009, p. 19). Assim, a elaboração de novas teorias acontece quando "Os saberes teóricos propositivos se articulam, pois, aos saberes da prática, ao mesmo tempo ressignificandoos e sendo por eles ressignificados". (PIMENTA, 2012, p. 31).

Embora se reconheça que os saberes docentes possuem naturezas diversas e que, antes de adentrarem nos cursos de formação inicial ou exercerem o magistério, os professores já possuem representações e experiências sobre o que é ser professor; compreendemos ser, na formação inicial, que os saberes docentes e as bases identitárias da profissão, são, sistematicamente construídas. A esse respeito, Pimenta (2009, p. 17-18), ressalta que:

Para além da finalidade de conferir uma habilitação legal ao exercício
profissional da docência, do curso de formação inicial se espera que forme o
professor. Ou que colabore para sua formação. Melhor seria dizer que colabore
para o exercício de sua atividade docente, uma vez que professorar não é uma
atividade burocrática para a qual se adquire conhecimentos e habilidades
técnico-mecânicas. Dada a natureza do trabalho docente, que é ensinar como
contribuição ao processo de humanização dos alunos historicamente situados,
espera-se da licenciatura que desenvolva nos alunos conhecimentos e
habilidades, atitudes e valores que lhes possibilitem permanentemente irem
construindo seus saberes-fazeres a partir das necessidades e desafios que o
ensino como prática social lhes coloca no cotidiano.

As diversas teorias da educação pensam sobre o papel do professor de acordo com os pressupostos teóricos, filosóficos e psicológicos que lhes servem de suporte, como versa Cunha (1992, p. 29), “A proposta de formação, como nos é dado ver, depende da concepção que se tem de educação e de seu papel na sociedade desejada ". Therrien (2016) postula que cada proposta de formação carrega uma intencionalidade, isto é, uma racionalidade que a fundamenta. $\mathrm{O}$ autor salienta que, nas últimas décadas, surgiram nas 
universidades novas propostas formativas. Tais propostas evidenciam a necessidade de superação do modelo de formação centrado na razão cognitivo-instrumental e tecnocrática, além do estabelecimento de uma formação centrada na razão intersubjetiva, dialógica e crítico-emancipatória.

É também nesse contexto que, para Zabalza (2004 apud VEIGA, 2010), a formação e o desenvolvimento profissional dos professores devem, antes de tudo, definir os sentidos e os significados que Ihes são subjacentes. Segundo o autor, esta definição suscita alguns questionamentos, são eles: Formação para quê? Quais são os conteúdos dessa formação? Quem são os agentes formadores e os destinatários? Que modelos e metodologias estão atrelados a este modelo de formação? Nessa perspectiva, entende-se que é buscando as respostas para estas questões que pode-se definir o conteúdo político da formação.

Para Freire (1996), formar o professor é muito mais do que treiná-lo para a realização de suas tarefas. É, sobretudo, prepará-lo científica e eticamente para desenvolver uma ação eminentemente política. É exercer a criticidade com vistas à superação da curiosidade ingênua pela curiosidade epistemológica, é reconhecer o valor das emoções e da sensibilidade, e conceber o formando como um sujeito produtor de saberes, pois "[...] quem forma se forma e re-forma ao formar e quem é formado formase e forma ao ser formado." (FREIRE, 1996, p. 23).

Por outro lado, como aponta Lima (2004, p. 92), “O conceito de formação está ligado ao trabalho do professor e à produção de si mesmo como profissional. " Isso significa que o trabalho cotidiano, desenvolvido pelo professor em sala de aula, pode também ser entendido como um espaço formativo; porquanto, é nesse espaço que os professores desenvolvem cotidianamente os saberes necessários à profissão, que criam e recriam o modo como ensinam e como adaptam sua ação pedagógica a cada turma de estudantes. Compreendemos, ainda que a formação docente é também coletiva, pois, pressupõe aprender com o outro, o outro aluno, o outro professor, o outro escola, o outro universidade, assim, “A formação é um processo coletivo de construção docente, na medida em que a prática decorrente dessa formação será necessariamente coletivizada [...]" (VEIGA, 2012, p. 28). 
Como apontamos anteriormente, não nos podemos esquecer de que a atividade de ensinar carrega um elemento formativo, o qual está presente no exercício diário da profissão e nas instituições de ensino onde os professores compartilham saberes e práticas, pois, “[...] os professores não se limitam a executar currículos, senão que também os elaboram, os definem, os reinterpretam." (PIMENTA, 2012, p. 43).

Nesta relação coletiva e de troca de experiências, os professores elaboram novas concepções sobre o ensino, refletem sobre o seu trabalho em sala de aula e reformulam suas práticas, ressignificando-as.

Ainda conforme Veiga (2012), quando nos reportamos à formação de professores é imprescindível discutirmos sobre alguns enunciados que nos ajudam a compreender essa temática. No primeiro enunciado, a autora explica que "[...] o processo de formação é multifacetado, plural; tem início e nunca tem fim. É inconcluso e autoformativo." (VEIGA, 2012, p. 26). Aqui, inferimos que o elemento humano expresso na atividade do ensino traz à baila a heterogeneidade dos alunos. Desse modo, o professor convive diariamente com estudantes, que antes de serem alunos são pessoas individuais, que possuem valores, crenças e visões diferenciadas sobre o mundo e que possuem, também, especificidades no modo como apreendem os conteúdos de ensino.

Ensinar em um contexto de heterogeneidade de alunos exige, igualmente, o domínio de uma heterogeneidade de práticas pedagógicas, isto é, distintos modos de abordar um mesmo conteúdo, de se comunicar, avaliar e se relacionar. Acrescentamos a isso o surgimento das novas tecnologias da informação que redirecionam o papel do professor e da instituição educativa, entendendo esta como instituição difusora de conhecimentos.

Poderíamos, então, afirmar que uma das principais tarefas do professor na sala de aula é envolver os alunos no trabalho idealizado por ele; é convencer, de modo criativo e encantador, que o que ele ensina tem uma relação com o mundo. Em vista disso, compreende-se que a atividade de ensinar é uma atividade complexa, o que torna também difícil e inconclusa a formação do professor. Assim, a "[...] formação assume uma posição de inacabamento, vinculada à história de vida dos sujeitos em permanente processo de construção humana, proporcionando sua preparação profissional. " (VEIGA, 2012, p. 26). 
No segundo enunciado, a autora em destaque diz que "A prática é o ponto de partida e de chegada da formação. " (VEIGA, 2012, p. 27); isto é, a formação de professores deve estar calcada no confronto entre as práticas educativas e as teorias da educação. Esta valorização da prática, portanto, não prescinde da fundamentação teórica. Com efeito, teoria e prática estabelecem entre si uma relação dialética e de interdependência. Neste ponto, julgamos também relevante destacar a compreensão de Pimenta e Anastasiou (2014, p. 84), quando expressam que considerar a prática social como ponto de partida e de chegada possibilita uma ressignificação dos saberes na formação de professores. A esse respeito, os autores salientam que

Como consequência, sua formação inicial só pode ocorrer com bases na aquisição de experiência dos formados (ou seja, tomar a prática existente como referência para a formação) e na reflexão sobre ela. Não é senão sobre essa base que o saber, enquanto elaboração teórica, se constitui.

No terceiro enunciado, Veiga (2012, p. 27), comunica que "O processo de formação significa uma articulação entre a formação pessoal e profissional". Isso significa que os professores não são apenas sujeitos cognitivos, mas também aqueles que possuem uma história de vida, valores, crenças emoções e angústias imbricadas na sua prática pedagógica. Como bem ensina Tardif (2014, p. 103), o professor é também um sujeito existencial que "[...] pensa a partir de sua história de vida não somente intelectual, no sentido rigoroso do termo, mas também emocional, afetiva, pessoal e interpessoal”.

No quarto e último enunciado, Veiga assinala que "O processo de formação é contextualizado histórica e socialmente e, sem dúvida, constitui um ato político. " (VEIGA, 2012, p. 27). Como toda prática social, a formação de professores ocorre em um contexto social determinado, e não pode ser compreendida fora dos condicionantes sociais, ideológicos, políticos e econômicos que interferem de maneira incisiva nesta formação. Ela traduz uma concepção sobre o que é educação e o que é ser professor - concepção subjacente ao modelo de sociedade que se deseja propagar. Assim, compreendemos, que “A afirmação profissional dos professores é um percurso repleto de lutas e de conflitos, de hesitações e de recuos." (NÓVOA, 1995, p. 21 apud ROLDÃO, 2007, p. 96).

Luckesi (2011), ao discutir sobre a importância da Didática na formação do educador, chama a atenção para o fato de que formar o professor não é apenas dotá-lo de instrumentos conceituais que lhe permitam transmitir os conteúdos da sua área de 
atuação, mas é, também, contribuir para que o professor desenvolva uma atitude crítica perante o mundo e sua própria prática pedagógica. No âmbito dessa discussão, o autor expressa o entendimento de que:

\begin{abstract}
Formar o educador é, a meu ver, seria criar condições para que o sujeito se prepare filosófica, científica e afetivamente para o tipo de ação que vai exercer. Para tanto serão necessárias não só aprendizagens cognitivas sobre os diversos campos de conhecimento que o auxiliem no desempenho do seu papel, mas especialmente - o desenvolvimento de uma atitude, dialeticamente crítica, sobre $\mathrm{o}$ mundo e sua prática educacional. $\mathrm{O}$ educador nunca estará definitivamente "pronto", formado, pois que a sua preparação, a sua maturação se faz no dia a dia, na meditação teórica sobre a sua prática. A sua constante atualização se fará pela reflexão diuturna sobre os dados de sua prática (LUCKESI, 2011, p. 28-29).
\end{abstract}

Como vemos, ele também destaca o papel da reflexão na formação docente. Assim, é importante salientar que a reflexão sobre a prática, na perspectiva de uma pedagogia crítica, não pode ser entendida como um momento individual do professor em que ele se dedica apenas à tarefa de pensar sobre as questões restritas à sala de aula, isto é, aspectos relativos ao planejamento das atividades. A reflexão crítica deve, antes de tudo, considerar o contexto social em que a atividade docente acontece, para que com apoio nessa contextualização e na identificação dos principais problemas postos na prática social dos alunos, o ensino possa articular-se com uma educação democrática. Como assinala Veiga (2012, p. 39):

A formação dos professores deve emergir de um processo de investigação, em que o pensar e o fazer são entrelaçados pelo diálogo, pela argumentação. $O$ projeto de formação deve ser, portanto, um produto que reflita a realidade interna, embora referenciada a um contexto social mais amplo.

Giroux (1990 apud PIMENTA, 2012, p. 27), também enfatiza a necessidade de uma reflexão crítica no ensino, quando entende que, formar professores significa formar “intelectuais críticos”, cuja reflexão transcende o universo da sala de aula, passando a considerar o contexto social em que a prática docente ocorre, isto é, os condicionantes políticos, econômicos e culturais que interferem nesta prática. Assim, entendemos que, conforme explica este autor, "A compreensão dos fatores sociais e institucionais que condicionam a prática educativa e a emancipação das formas de dominação que afetam nosso pensamento e nossa ação não são espontâneas e nem se produzem naturalmente." (PIMENTA, 2012, p. 33). 


\section{Tendências formativas na formação inicial de professores}

Como apontado, a proposta de formação docente é definida conforme o entendimento que se tem acerca da educação e do papel do professor na sociedade. Neste ponto, traremos as diversas tendências que orientam a formação inicial de professores, enquanto relacionamos cada uma delas ao modelo de racionalidade que the é subjacente. Veiga (2012), expressa que, no Brasil, há duas grandes tendências formativas fundamentadas em distintas concepções de educação e de docência: a que concebe o professor como agente social e a que o concebe como tecnólogo do ensino.

A formação do professor como agente social desenvolve-se na perspectiva de uma educação crítica e emancipatória e requer, para sua efetivação, condições dignas de trabalho, valorização dos professores, organização da categoria por meio de entidades sindicais, bem como o investimento na carreira. Nesta tendência formativa, a educação, concebida como prática social, tem como principal tarefa contribuir para a emancipação. Assim, podemos afirmar que "O referencial para as propostas de formação dos professores visa à construção coletiva de um projeto alternativo capaz de contribuir, cada vez mais, para o desenvolvimento de uma educação de qualidade para todos." (VEIGA, 2012, p. 19).

A autora elenca os principais pontos que definem a formação do professor como um agente social: construção e domínio sólidos dos saberes da docência; unicidade entre teoria e prática; a ação coletiva visando à melhoria do trabalho pedagógico; maior controle sobre o trabalho pedagógico, valorizando a autonomia do professor; a explicitação da dimensão sociopolítica da educação e a compreensão das competências dos professores como ações contextualizadas que traduzem um saber (VEIGA, 2012).

Esta formação é, portanto, um projeto coletivo que não pode se concretizar na perspectiva de uma racionalidade cognitivo-instrumental, monológica e tecnocrática. Assim, a racionalidade que fundamenta a formação do professor como agente social está centrada em uma pedagogia crítica que advoga pelo diálogo intersubjetivo, expressa a crítica transformadora e valoriza o docente enquanto um profissional construtor de saberes os quais definem a identidade do professor. Podemos chamar esta racionalidade de pedagógica e caracterizá-la como um espaço de formação crítica do professor. 
Para a racionalidade pedagógica, o professor não é um técnico do ensino, mas, antes de tudo, um profissional mediador de aprendizagens significativas. A competência para ensinar situa-se, portanto, além do domínio dos conhecimentos de sua área, requerendo a transformação pedagógica dos conteúdos de ensino, para que estes possam ser apreendidos pelos estudantes. Assim, a mediação pedagógica realiza-se por meio do diálogo intersubjetivo entre docentes e alunos, em que a linguagem passa a ser entendida como ação comunicativa produtora de sentidos e significados. De acordo com Therrien (2012, p. 114-115):

\begin{abstract}
Esse olhar sobre o docente como profissional da educação, ou seja, como educador, conduz a percebê-lo para além de uma função de mero "Instrutor" responsável pelo repasse objetivo, normativo e instrumental de conhecimentos produzidos pela humanidade e socialmente reconhecidos, postos à disposição da consciência e da inteligência do aprendiz. A postura desse mediador como "profissional do saber" o projeta para função de "Formador" de sujeitos situados no mundo da vida, onde hão de descobrir os múltiplos saberes e significados que regem a vida da sociedade. A postura dialógica constitui-se em fundante de aprendizagens que afetam a identidade desses sujeitos.
\end{abstract}

Em contrapartida, a formação do professor como um tecnólogo do ensino busca a correspondência com o mercado globalizado. Neste sentido, a formação limita-se ao desenvolvimento meramente técnico da profissão, limitando-se ao saber-fazer. Como enfatiza Veiga (2012, p. 17), a perspectiva da formação centrada nas competências “[...] é restrita e prepara, na realidade, o prático, o tecnólogo, isto é, aquele que faz, mas não conhece os fundamentos do fazer, [...] esquecendo-se da relação com a realidade social mais ampla". Os principais pontos que definem a formação do professor como tecnólogo do ensino são: formação ligada à sociedade globalizada e neoliberal; parte de um projeto político-educacional maior, de abrangência internacional, com orientações advindas do Banco Mundial e, por fim, parte de uma concepção puramente economista de educação, onde esta é entendida como um instrumento gerador de produtividade (VEIGA, 2012).

Inferimos que a ideia de racionalidade fundante deste modelo de formação está centrada na "pedagogia das competências". (RAMOS, 2011). Esta, desde os anos de 1990, ocupa lugar de destaque no ideário educacional brasileiro. Nessa ótica, a formação do professor, longe de ser um processo crítico, coletivo e emancipador, passa a ser entendida como algo subjetivo, individual, não dialógico e restritamente técnico. Esta é a tendência de formação que predomina da sociedade capitalista e pós-moderna, pois ela 
se harmoniza aos interesses do mercado. No contexto de uma sociedade capitalista, a formação de professores está cerceada pelos ditames do mercado, transformando-se também em uma mercadoria. O professor é reconhecido não como um profissional que produz saberes, mas como um profissional de competências. Nessa perspectiva:

Competências no lugar dos saberes profissionais deslocam do trabalhador para o local de trabalho a sua identidade, ficando este vulnerável à avaliação e controle de suas competências definidas pelo "posto de trabalho". Se estas não se ajustam ao esperado, facilmente poderá ser descartado. Será assim que podemos identificar um professor? (PIMENTA, 2012, p. 49).

Reduzir a formação dos professores ao domínio de competências é desqualificar esta formação, é transformar os professores “[...] em tutores e monitores da aprendizagem. Neste caso, os saberes que necessitam são simplificados em competências, o que resulta em menos investimento em sua formação. " (PIMENTA, 2012, p. 54). Assim, o aligeiramento da formação reflete o próprio funcionamento do capital e das forças produtivas.

Para o capitalismo, a racionalização do tempo de trabalho representa um nível elevado de produção. Assim, racionalizar, também, o tempo de formação do professor significa formar em grande escala, ainda que essa formação seja precária, haja vista, que essa precariedade na formação reflete de forma incisiva no trabalho desenvolvido pelo professor em sala de aula, e, quando os resultados desse trabalho não atendem aos parâmetros estabelecidos pelo Estado, “[...] responsabilizam-se os professores, esquecendo-se que eles são também produto de uma formação desqualificada historicamente[...]" (PIMENTA, 2012, p. 48).

Contrariando essa concepção puramente mercadológica da formação docente, calcada na Pedagogia das Competências, reiteramos a ideia de que, como nos indica Veiga (2012), formar professores implica compreender a importância do papel da docência, propiciando uma profundidade científica-pedagógica a esses profissionais.

Portanto, a formação do professor configura-se como um percurso construtivo de aquisição e de produção dos saberes docentes, os quais, mediante reflexão sistemática e confronto com as práticas educativas, servirão de fundamento para a constituição das ações pedagógicas do professor. Os diversos saberes que integram a formação docente retratam a própria complexidade do ensino, este, como uma prática social só poderá ser compreendido na sua integralidade. 
García (1995), também, fomenta uma discussão interessante sobre as diversas tendências que orientam a formação de professores. O autor faz questão de salientar que cada tendência traz diferentes estruturas de racionalidade, as quais denotam variadas concepções de escola, currículo e ensino. Desse modo, as concepções sobre o professor podem variar conforme as diferentes abordagens, paradigmas ou orientações. "Assim, podemos observar numerosas, e por vezes contraditórias, imagens do professor: eficaz, competente, técnico, pessoa, profissional, sujeito que toma decisões, investigador, sujeito que reflete, etc." (GARCíA, 1995, p. 30). Explanaremos, brevemente, sobre estas tendências, procurando demonstrar as características e as implicações de cada uma. As tendências são as seguintes: acadêmica, a tecnológica, a personalista, a prática e a socialreconstrucionista.

A tendência acadêmica tem como principal característica a centralidade nos conteúdos de ensino, ou seja, a formação docente está centrada no domínio desses conteúdos, e tem como principal objetivo formar um professor especializado em uma ou mais disciplinas. Para Garcia (1995, p. 33), nesta tendência, a formação docente consiste, principalmente, na “[...] transmissão de conhecimentos científicos e culturais de modo a dotar os professores de uma formação especializada, centrada principalmente no domínio dos conceitos e estrutura disciplinar da matéria em que é especialista". A centralidade nos conteúdos situa o aspecto pedagógico em uma posição menos importante, o ensino, pois, é concebido como transmissão do conhecimento historicamente acumulado. Logo, nesta tendência, aprender a ensinar não é um aspecto relevante na formação docente. Por supervalorizar o conteúdo de ensino, essa tendência desconsidera as diversas transformações didáticas que precisam ser realizadas pelo professor para que esses conteúdos possam ser assimilados pelos estudantes.

A tendência tecnológica concebe o ensino como uma ciência aplicada e o professor é um técnico capaz de transformar os conteúdos dessa ciência em regras gerais para a ação em sala de aula. Por isso, "Esta orientação foca a sua atenção no conhecimento e nas destrezas necessárias para o ensino, decorrendo tais destrezas da investigação processo-produto." (GARCíA, 1995, p. 34). A formação de professores é centrada nos treinos e na aquisição de destrezas, competências e condutas desejáveis ao ensino. 
A aprendizagem dessas competências ocorre por meio de materiais auto instrucionais denominados de módulos instrucionais. São princípios centrais que norteiam esta formação: o programa de ensino individualizado, o controle da qualidade desta formação, a clareza dos objetivos e a avaliação dos resultados. Esta orientação encontra na Psicologia Comportamentalista sua principal fonte de inspiração.

A tendência personalista recebe influências da Psicologia Humanista e da Fenomenologia. O ponto central desta tendência é a formação do professor como pessoa e ser humano. Com efeito, o melhor professor seria aquele que aprendeu a usar sua personalidade e suas qualidades para o desenvolvimento satisfatório do ensino e da aprendizagem; aquele que possui autoconceito positivo e a maturidade necessária para o enfrentamento das situações da sala de aula.

Como aponta García (1995, p. 38), “Um bom professor é uma pessoa, uma personalidade única, um facilitador que cria condições que conduzem à aprendizagem e, para o conseguir, os professores devem conhecer os seus estudantes como indivíduos". Em razão disso, o comportamento do professor depende da maneira como ele se percebe no mundo, na relação consigo mesmo e com as pessoas. Por isso, o autoconceito é tão importante. O papel da formação não é o de ensinar um método a todos os professores, mas sim, o de levar cada docente a se descobrir na profissão, auxiliando-o no estabelecimento da sua maneira de ensinar. Conforme ainda salienta García (1995, p. 38):

De acordo com estes pressupostos, a formação de professores deixa de ser um processo de ensinar aos futuros professores como ensinar, sendo mais importante a auto-descoberta pessoal, a tomar consciência de si próprio. Dessa forma, a formação de professores adquire algumas dimensões pessoais, relacionais, situacionais, e instrucionais que é necessário considerar para facilitar a cada sujeito seu desenvolvimento pessoal.

A tendência prática tem como principal arcabouço teórico o pragmatismo desenvolvido por John Dewey. Segundo esta tendência, a formação de professores deve ser entendida como um continuum de aprendizagem da arte e do ofício do ensino. Assim, as situações práticas e as vivências envolvendo o cotidiano da sala de aula assumem um papel relevante na formação do professor. A experiência é a única fonte de conhecimento sobre o ensino e somente ela é capaz de preparar os professores para a complexa tarefa de ensinar. Eis por que a prática é mais importante do que a teoria. A 
observação da prática de professores mais experientes também assume relevância na formação. Nessa perspectiva, García (1995, p. 39) explica

\begin{abstract}
O modelo de aprendizagem associado a esta orientação na formação de professores é a aprendizagem pela experiência e pela observação. Aprender a ensinar é um processo que se inicia através da observação de mestres considerados "bons professores", durante um período de tempo prolongado. Isso significa trabalhar com um mestre durante um determinado período de tempo ao longo do qual o aprendiz adquire as competências práticas e aprende a funcionar em situações reais.
\end{abstract}

Outro autor que fundamenta esta tendência formativa é Donald Schön. Segundo Pimenta (2012), Schön propõe que a formação dos profissionais, e não somente dos professores, ocorra por meio da reflexão-na-ação. No caso dos docentes, a reflexão na ação possibilitaria a estruturação de um repertório de soluções que auxiliariam os professores na resolução dos problemas do cotidiano da sala de aula. Assim, ao postular a epistemologia da prática, Schön pede que se atente para a valorização da prática profissional como um momento de reflexão, problematização e de elaboração de conhecimento. Este que os professores elaboram na prática, “[...] é o conhecimento tácito, implícito, interiorizado, que está na ação e que, portanto, não a precede. É mobilizado pelos profissionais no seu dia a dia, configurando um hábito." (PIMENTA, 2012, p. 23).

Observa-se, nesse contexto, que a grande crítica que os autores fazem a esta tendência diz respeito à supervalorização da prática na formação docente, o que contribui para o entendimento de que o docente é um mero executor de tarefas. Outro aspecto que compõe esta crítica está relacionado ao conceito de reflexão na ação, proposto por Schön. Segundo os autores, este conceito acarreta uma visão reducionista do papel do professor, visto que a reflexão realizada por ele não pode se restringir aos problemas da sala de aula, devendo considerar o contexto histórico e social onde ocorre o ensino.

Por último, temos a tendência social-reconstrucionista, que estabelece relação direta com a teoria crítica da educação e concebe o professor como um agente social que desempenha um papel ético e político na sociedade. Nesta perspectiva, a formação do professor é influenciada pelo contexto social onde ocorre, pois é historicamente determinada e carrega um conteúdo político que perpassa as práticas formativas. Neste 
enfoque, formar professores é um projeto social, ultrapassa, pois, a dimensão puramente técnica da docência. Conforme García (1995, p. 44), esse projeto “[...] incorpora um compromisso ético e social de procura de práticas educativas e sociais mais justas e democráticas, sendo os professores concebidos como ativistas políticos e comprometidos com o seu tempo".

Neste sentido, a reflexão realizada pelo educador não é entendida como algo natural, individualizado ou mecânico, isto é, ela não se mostra como qualidade inata do docente, não é determinada biológica ou psicologicamente, mas socialmente. Isso significa que as relações sociais determinam o nível de reflexão realizado pelos professores, bem como o modo como estes refletem sobre o trabalho que desenvolvem. Esta compreensão crítica da formação docente traz também um entendimento igualmente crítico do currículo e da educação. Como enfatizam Giroux e Mclaren (1986 apud GARCíA, 1995, p. 45), “Um currículo de formação de professores como forma política e cultural defende que as dimensões sociais, culturais, políticas e econômicas são as principais categorias para compreender a escola contemporânea".

Ao relacionarmos as tendências formativas expressas por García (1995) com os seus respectivos modelos de racionalidade, consideramos importante destacar o fato de que as quatro primeiras tendências (acadêmica, tecnológica, personalista e prática) denotam características intimamente veiculadas ao modelo da racionalidade cognitivoinstrumental. Em síntese, é lícito dizer que, na tendência acadêmica, o núcleo central é a transmissão do conteúdo de ensino; na tecnológica, é a aquisição de competências e a aplicação fidedigna da ciência; na personalista, é o desenvolvimento do ser humano como pessoa; e na prática, é a experiência como fonte de conhecimento. Assim, compreendemos que, em nenhuma dessas tendências, a dimensão histórica, social e política da docência é considerada; a formação do professor, é entendida como um projeto separado do contexto social mais amplo.

Desse modo, a racionalidade que fundamenta estas tendências é expressa como uma racionalidade técnica, fechada em si mesma, pois não dialoga com os condicionantes sociais, políticos, econômicos e culturais que refletem na formação docente. Na concepção de Martinazzo (2005, p. 64), ela se assentada numa, “[...] razão logocêntrica que tem como arcabouço a Filosofia da consciência ou o exercício de uma competência 
cognitiva e não, necessariamente, uma competência interativa, discursiva e comunicativa".

Em contrapartida, a tendência social-reconstrucionista, busca evidenciar o caráter político da formação de professores, relacionando-se com a concepção crítica da educação. Esta tendência rompe com os pressupostos da racionalidade técnica ou cognitivo-instrumental, apontando caminhos para o desenvolvimento de uma racionalidade pedagógica que servirá de embasamento para a formação do educador crítico. Esta racionalidade considera os diversos tipos de saberes que devem permear o processo formativo e concebe o docente como um profissional de saberes e não apenas de fazeres, um intelectual crítico, cuja reflexão transcende o nível dos problemas da sala de aula.

Sabe-se que, formar o professor com suporte no paradigma da racionalidade pedagógica pressupõe o diálogo intersubjetivo entre os diversos campos de conhecimento atuantes na formação, e o reconhecimento da prática docente, como espaço profícuo de elaboração de novos saberes. Nessa concepção formativa, o ensino é uma prática social complexa, exigindo para sua compreensão o emprego de uma razão crítica, comunicativa e emancipadora.

\section{CONSIDERAÇÕES FINAIS}

Com efeito, o estudo sobre a formação docente nos leva a sinalizar sobre a importância da formação inicial no processo de constituição dos saberes docentes. Em uma perspectiva crítica da educação, fundamentada numa racionalidade pedagógica, esta primeira etapa formativa se concretiza não na prescrição de regras normativas e instrumentais acerca do fazer pedagógico, mas nas possibilidades que ela oferece de ensaio na profissão, de reflexão sobre a prática a luz das teorias e de socialização dos conhecimentos e dos saberes necessários à atividade do ensino.

Nesta acepção, formar professores não é apenas prepará-los para transmitir conteúdos curriculares, mas é, sobretudo, formá-los para mediar aprendizagens significativas, para difundir o que a humanidade constrói e o que ela já construiu em termos de conhecimentos, de bens culturais; é ainda prepará-los para que eles possam refletir criticamente sobre o próprio fazer e, com base nisso, estabelecer formas 
inovadoras de ser, entender e viver a docência. Sua característica coletiva nos indica, ainda, que ela também pode ser entendida como um espaço de socialização profissional, de inserção na cultura docente, o que envolve o acesso ao conjunto de saberes que caracterizam a profissão.

\section{REFERÊNCIAS}

ALMEIDA, Maria Isabel. Formação do professor do ensino superior: desafios e políticas institucionais. 1. ed. São Paulo: Cortez, 2012.

CUNHA, Maria Isabel da. O bom professor e sua prática. 2. ed. Campinas: Papirus, 1992.

FREIRE, Paulo. Pedagogia da autonomia: saberes necessários à prática educativa. São Paulo: Paz e Terra, 1996.

GARCÍA, Carlos Marcelo. Formação de professores: para uma mudança educativa. Portugal: Porto Editora, 1995.

LIMA, Maria Socorro Lucena. Educação, educação permanente; Formação, formação contínua. In: LIMA, Maria Socorro Lucena; ALMEIDA, Ana Maria Bezerra de; SILVA, Silvinha Pimentel. Dialogando com a escola: reflexões do estágio e da ação docente nos cursos de formação de professores. 2. ed. Fortaleza: Demócrito Rocha, 2004.

LUCKESI, Cipriano Carlos. O papel da didática na formação do educador. In: CANDAU, Vera Maria (org.). A didática em questão. 31 ed. Petrópolis: Vozes, 2011.

MAGALHÃES. Maria de Lourdes Tavares. Os saberes pedagógicos de professores do curso de pedagogia da Universidade Regional do Cariri /URCA: um estudo sobre a racionalidade pedagógica nas narrativas docentes. Dissertação de (Mestrado em Educação Brasileira) - Programa de Pós-Graduação em Educação Brasileira, Universidade Federal do Ceará, Fortaleza, 2018.

MARTINAZZO. Celso José. Pedagogia do entendimento intersubjetivo: razões e perspectivas para uma racionalidade comunicativa na pedagogia. ljuí: Editora Unijuí, 2005.

MENDES SOBRINHO, José Augusto de Carvalho; CARVALHO, Marlene Araújo de. Formação de professores e práticas docentes. Belo Horizonte: Autêntica, 2006.

PIMENTA, Selma Garrido. Professor: formação, identidade e trabalho docente. In: PIMENTA, Selma Garrido (org.). Saberes Pedagógicos e Atividade Docente. 7. ed. São Paulo: Cortez, 2009.

PIMENTA, Selma Garrido. Professor reflexivo: construindo uma crítica. In: PIMENTA, Selma Garrido; GHEDIN, Envandro (org.). Professor reflexivo no Brasil: gênese e crítica de um conceito. 7. ed. São Paulo: Cortez, 2012. 
PIMENTA, Selma Garrido; ANASTASIOU, Lea das Graças Camargo. Docência no ensino superior. 5. ed. São Paulo: Cortez, 2014.

RAMOS, Marise Nogueira. A pedagogia das competências: autonomia ou adaptação? São Paulo: Cortez, 2011.

ROLDÃO, Maria do Céu. Função docente: natureza e construção do conhecimento profissional. Revista Brasileira de Educação, Rio de Janeiro, v. 12, n. 34, jan./abr. 2007.

SEVERINO, Antônio Joaquim. Metodologia do trabalho científico. 23. ed. São Paulo: Cortez, 2007.

SILVA, Rita de Cássia. O professor, seus saberes e suas crenças. In: GUARNIERI, Maria Regina. Aprendendo a ensinar: o caminho nada suave da docência. 2 ed. Campinas: Autores Associados, 2005.

TARDIF, Maurice. Saberes docentes e formação profissional. 16. ed. Petrópolis: Vozes, 2014.

THERRIEN, Jacques. Docência profissional: a prática de uma racionalidade pedagógica em tempos de emancipação de sujeitos. In: D'ÁVILA, Cristina; VEIGA, Ilma Passos Alencastro (org.). Didática e docência na educação superior: implicações para a formação de professores. 1. ed. Campinas: Papirus, 2012.

THERRIEN, Jaques; DIAS, Ana Maria Iorio, LEITINHO, Meirecele Calíope. Docência universitária. Revista Em Aberto, Brasília, v. 29, n. 97, set./dez. 2016. Disponível em: http://emaberto.inep.gov.br/index.php/emaberto/article/view/2952. Acesso em: 01 nov. 2017.

VEIGA, Ilma Passos Alencastro. Alternativas pedagógicas para a formação do professor da educação superior. In: VEIGA, IIma Passos Alencastro; VIANA, Cleide Maria Quevedo Quixadá. Docentes para a educação superior: processos formativos. Campinas: Papirus, 2010.

VEIGA, Ilma Passos Alencastro. A aventura de formar professores. 2. ed. Campinas: Papirus, 2012.

VEIGA, Ilma Passos Alencastro. Formação de professores para a educação superior e a diversidade da docência. Revista Diálogos em Educação, Curitiba, v. 14. maio/ago. 2014. p. 327-342. 